\title{
Comportamento de Ficus na arborização urbana do bairro Santa Clara, Santarém/Pará
}

Este trabalho teve como objetivo a realização de um inventário do tipo censo quali-quantitativo no bairro Santa Clara, município de Santarém/PA acerca da espécie Ficus sp. Coletaram-se dados em relação à sua altura, DAP (diâmetro à altura do peito), DC (diâmetro de copa), relação com a fiação, recomendação quanto ao manejo, posição e sanidade da raiz, do fuste e da copa. Foram encontrados 54 indivíduos de Ficus, sendo que a maioria (44\%) apresentou porte médio com afloramento na calçada em $83 \%$ dos casos. Em relação a sanidade, $57 \%$ das raízes estavam com algum nível de podridão e $43 \%$ não apresentaram problemas. A sanidade do fuste mostrou-se favorável com $96 \%$ de indivíduos sem interferência e $4 \%$ com podridão. Na fiação, $56 \%$ não estavam em contato com a rede elétrica e $44 \%$ se encontravam presentes ou com potencial risco para a fiação. Tendo por base essas condições, a recomendação de manejo indicou para $81 \%$ dos casos necessidade de poda, $6 \%$ para remoção e $13 \%$ para os indivíduos que não apresentaram necessidade de tratos silviculturais. Conclui-se que a utilização de Ficus não é adequada à arborização próximo a fiação e estruturas pavimentadas, sendo aconselhável sua substituição de forma gradativa.

Palavras-chave: Amazônia; Planejamento ambiental; Afloramento de raiz.

\section{Behavior of Ficus in the urban afforestation of Santa Clara district, Santarém/Pará}

\begin{abstract}
The objective of this work was to carry out a qualitative and quantitative census inventory in Santa Clara neighborhood, Santarém/PA, Brazil, about Ficus sp. Data were collected in relation to its height, DBH, crown diameter, relation with the spinning, recommendation regarding the management, position and health of the root, stem and crown. Fifty-four Ficus individuals were found, most of them (44\%) presented medium size with sidewalk outcrops in $83 \%$ of the cases. Regarding sanity, $57 \%$ of the roots had some level of rot and $43 \%$ had no problems. The health of the stem was favorable with $96 \%$ of individuals without interference and $4 \%$ with rot. In the wiring, $56 \%$ were not in contact with the power grid and $44 \%$ were present or with potential risk to the wiring. Based on these conditions, the management recommendation indicated that $81 \%$ of the cases required pruning, $6 \%$ for removal and $13 \%$ for individuals who did not require silvicultural treatments. It is concluded that the use of Ficus is not suitable for afforestation near spinning and paved structures, and its gradual replacement is advisable.
\end{abstract}

Keywords: Amazon; Environmental planning; Root outcrop.

Topic: Ciências Florestais

Reviewed anonymously in the process of blind peer
Received: 09/12/2019

Approved: $12 / 01 / 2020$
Tayane Pedroso Fernandes (iD)

Universidade Federal do Oeste do Pará, Brasil

http://lattes.cnpq.br/3824030801045675

http://orcid.org/0000-0003-2359-5118

tayane.fernandes33@gmail.com

\section{Lucas Cunha Ximenes (iD)}

Universidade Federal do Oeste do Pará, Brasi

http://lattes.cnpq.br/0879648522574450

http://orcid.org/0000-0002-3568-4401

lucasximenesflorestal@gmail.com
Referencing this:

FERNANDES, T. P.; XIMENES, L. C.. Comportamento de Ficus na arborização urbana do bairro Santa Clara, Santarém/Pará. Revista Ibero Americana de Ciências Ambientais, v.11, n.1, p.29-39, 2020. DOI: http://doi.org/10.6008/CBPC2179-6858.2020.001.0004 


\section{INTRODUÇÃO}

Sabe-se que o componente arbóreo se constitui como um importante instrumento ao bem-estar humano, podendo ser utilizado como uma ferramenta para medir e elevar os níveis de qualidade de vida de uma população. No entanto, quando inseridas de forma incorreta, sem contar com um estudo prévio e planejamento adequado, as árvores podem acarretar em problemas para as infraestruturas dos espaços urbanos, bem como para as pessoas (CABRAL, 2013).

O desenvolvimento da expansão urbana esteve intimamente ligado a diversos processos de supressão e substituição do componente arbóreo por estruturas que caracterizam as cidades. Entretanto, a rapidez pelo qual esse processo se deu não favoreceu a implementação do uso adequado desse espaço, principalmente no que diz respeito à sua arborização (CABRAL, 2013). Esse processo de transformação do espaço e construção das cidades é visto como uma conquista do ser humano em busca de civilidade, o que neste contexto, ocorre através da substituição do ambiente natural por um meio cada vez mais artificializado, como a citadina (ÁVILA, 2015).

Com a transição do espaço rural para o urbano, ocorreram mudanças em diversos processos que resultaram em impacto ambiental (COELHO, 2004). Tal cenário, pode ser observado no uso de espécies não apropriadas ao espaço urbano, resultando, muitas vezes, em uma problemática tanto no rompimento de calçadas (ocasionado por suas raízes); quanto para a fiação elétrica, devido ao conflito dado pelo crescimento de sua copa e risco de queda no caso de apodrecimento de seus galhos (CABRAL, 2013).

Junto ao crescimento da arborização urbana, ocorreu ao mesmo passo a implantação de espécies exóticas das mais diversas origens, de modo a serem encontradas comumente como parte deste cenário (SANTOS et al., 2017). Apesar de presentes na arborização das cidades, estas espécies, por terem sua natureza adaptada às condições de seu ambiente de origem, quando transportadas para outro ecossistema, podem agir como dominantes no local inserido, extinguindo parte da biodiversidade local (BLUM, 2008).

Dentre as espécies exóticas presentes na arborização urbana, o Ficus $s p$. destaca-se por ser considerado frequente em estudos que realizam inventários sobre o componente arbóreo de várias cidades, sendo, muitas vezes, um dos mais abundantes neste meio (CARVALHO et al., 2013; SILVA et al., 2018; MOURA et al., 2009; LIRA FILHO et al., 2009; JORGE et al., 2017; MARIA, 2017). A recorrência do uso do Ficus na arborização urbana do país pode ser atribuída ao seu uso para fins paisagísticos, devido, principalmente, à sua notável copa verde e imponente (SOUZA et al., 2005), sendo que a frequência de sua utilização neste espaço justifica um estudo mais aprofundado sobre seu comportamento em relação ao meio.

Pertencente à família Moraceae, o Ficus é também conhecido como figueirinha e possui altura que pode variar entre 20 a 30 metros, sendo oriundo da Índia e Filipinas (MUSEU NACIONAL, 2019). Sua utilização mais comum em relação aos seus componentes é a extração de resina (goma de benjamin) para a produção de incenso (LIMA et al., 2005). No entanto, estudos mais recentes destacam a possibilidade da utilização de seus componentes (folhas, caule e raízes) para a extração de substâncias com potenciais antioxidantes e antimicrobianos (IMRAN et al., 2014). Com isso, o presente estudo tem como objetivo avaliar o 
comportamento de indivíduos de Ficus na arborização urbana do bairro Santa Clara, situado no município de Santarém, Pará.

\section{MATERIAIS E MÉTODOS}

\section{Caracterização da área}

Localizada ao oeste do estado do Pará, Santarém possui uma área de $17.898,389 \mathrm{~km}^{2}$, sendo que destes, 77 km² estão em perímetro urbano, com população estimada em 304.589 mil habitantes e densidade demográfica de 12,87 habitantes $/ \mathrm{km}^{2}$ (IBGE, 2019). O clima de Santarém é classificado como tropical quente e úmido, com temperatura média anual de $25^{\circ}$ a $28^{\circ} \mathrm{C}$ e umidade relativa média do ar de $86 \%$, além de elevada ocorrência de pluviosidade média (1920 mm) ao longo do ano (IBGE, 2015). De acordo com a classificação climática de Köppen e Geiger, o clima é tido como Am, caracterizado por ser tropical úmido ou subúmido, com alto índice pluviométrico e breves períodos secos (EMBRAPA, 2019). Em relação a sua arborização, estima-se que se encontra $43,3 \%$ arborizada, distribuída em um total geral de $7,8 \%$ das vias públicas urbanizadas da cidade (IBGE, 2010).

O bairro Santa Clara (Figura 1) é um espaço que abriga o centro comercial da cidade, sendo, portanto, um dos principais bairros do município. Ao longo de suas principais vias, é notável o uso de árvores que possibilitam maior conforto térmico aos pedestres e veículos. No entanto, não houve qualquer planejamento para sua implantação e não há Plano Diretor que indique diretrizes para seu estabelecimento, o que justifica a escolha do bairro para a condução desta pesquisa.

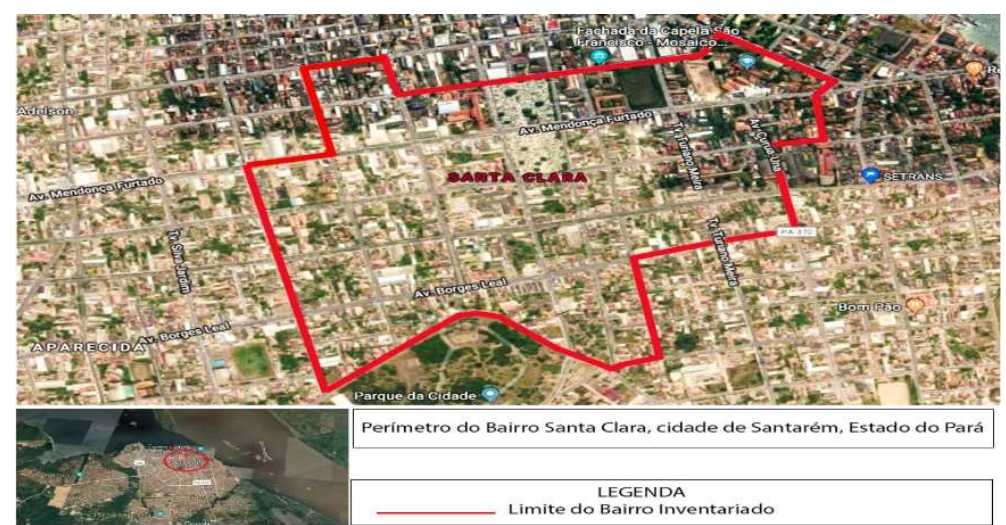

Figura 1: Localização da área de estudo no município de Santarém, Pará. Fonte: Google Earth (2019).

\section{Coleta e análise de dados}

O método de inventário utilizado para a coleta de dados dos indivíduos de Ficus foi do tipo censo (100\%), de caráter qualitativo-quantitativo. Os dados foram coletados no mês de setembro de 2018, no bairro Santa Clara, município de Santarém, juntamente ao Projeto Floresta Urbana, contando com a utilização de planilhas estruturadas para verificar o nome da espécie, $\mathrm{Ht}$ - altura total (m), DAP - diâmetro à altura do peito $(\mathrm{cm}), \mathrm{DC}$ - diâmetro de copa $(\mathrm{m})$, relação com a fiação, recomendação quanto ao manejo, posição e sanidade da raiz, fuste e copa. 
O Projeto Floresta Urbana é um projeto resultante da união de esforços entre a Universidade Federal do Oeste do Pará (UFOPA) e a Prefeitura Municipal de Santarém, para a realização de levantamento arbóreo ao decorrer de vias públicas pavimentadas em 10 bairros da cidade, a fim de coletar informações sobre as espécies, sanidade e localização das mesmas, objetivando a elaboração do tão necessário projeto de arborização da cidade.

O auxílio de um mapa possibilitou que os dados fossem coletados de acordo com a delimitação dos limites do bairro, definidos nas imagens disponibilizadas pelo Google Earth. O critério de inclusão utilizado para a inserção dos indivíduos deste estudo foi de acordo com sua altura total ( $\mathrm{Ht} \geq 1,5 \mathrm{~m})$. Para a análise dos dados qualitativos, como contato com a fiação, recomendação de manejo e sanidade e posição das raízes, fuste e copa dos indivíduos de Ficus, utilizou-se critérios visuais de avaliação. As medidas para a coleta dos dados quantitativos, como DAP e diâmetro de copa, foram tomadas com o auxílio de trena e fita métrica. A altura foi estipulada à distância, através de estimativa visual orientada por uma vareta de 1 metro posicionada ao lado da árvore, de acordo com metodologia proposta por Silva et al. (1979).

No que diz respeito ao diâmetro da copa, para fins de análise e processamento, realizou-se sua distribuição em três classes diamétricas de copa seguindo a classificação dada por Biondi e Leal (2009), sendo elas: Classe I $(0 \leq D C<2,5 \mathrm{~m})$, Classe II $(2,5 \leq \mathrm{DC}<5 \mathrm{~m})$ e Classe III (DC $\geq 5 \mathrm{~m})$. De acordo com Lacerda (2011), a classificação por porte do componente arbóreo é de difícil estabelecimento, no entanto é extremamente necessária para a escolha de espécies que se adequem de forma apropriada ao espaço urbano. Portanto, para este estudo, optou-se por distribuí-las baseado na classificação de Biondi e Leal (2009), em Classe I: Ht $\leq 5 \mathrm{~m}$ e Classe I de DC para pequeno porte; Classe II: $5 \mathrm{~m}<\mathrm{Ht} \leq 10 \mathrm{~m}$ e Classe II de DC para médio porte; e Classe III: Ht > 10 m e Classe III de DC para indivíduos de grande porte.

Para fins de classificação de coleta, a planilha apresentava-se estruturada da seguinte forma: data; nome da espécie; altura total $(\mathrm{m})$; diâmetro à altura (DAP) em cm; diâmetro de copa (DC) em metros; posição do fuste $(0=$ retilíneo, $1=$ inclinado para a residência, $2=$ inclinado para a rua) e copa $0=$ sem inclinação, $1=$ inclinada para residência, $2=$ inclinada para rua); posição das raízes ( $0=$ sem afloramento, $1=$ sem afloramento com rachaduras, $2=$ afloramento contido, $3=$ afloramento com rachaduras); sanidade do fuste e da copa ( 0 = sadia; $1=$ parasita, $2=$ cupim, $3=$ podre); sanidade das raízes ( $0=$ sadia, $1=$ estrangulada, $2=$ cortada, $3=$ podre); contato com a fiação ( $0=$ ausente, $1=$ potencial, $2=$ presente); e recomendação de manejo ( $0=$ ausente, $1=$ poda, $2=$ remoção e $3=$ =substituição). Os dados provenientes do censo foram plotados e processados utilizando planilhas eletrônicas e analisados por meio de estatística descritiva.

\section{RESULTADOS E DISCUSSÃO}

Foram encontrados um total de 54 indivíduos de Ficus, sendo que destes, 47 estavam presentes nas calçadas e 7 se encontravam distribuídos pelo meios-fios. A predominância da espécie nas calçadas do bairro pode ser resultante da oferta de espaço maior se comparado aos meios fios e devido a característica da espécie de altura e diâmetro do fuste. 


\section{Diâmetro e posição de fuste e copa}

Os dados de DAP (cm) foram agrupados em classes diamétricas distribuídas em intervalos de $10 \mathrm{~cm}$ (Figura 2). A maior concentração se deu nos intervalos de 45 a 55 cm, com 14 e 10 indivíduos, respectivamente, indicando que o maior número de indivíduos nestes intervalos, principalmente nas classes intermediárias de tamanho, demonstra que o fuste é característico de árvores com maior maturidade em seu desenvolvimento.

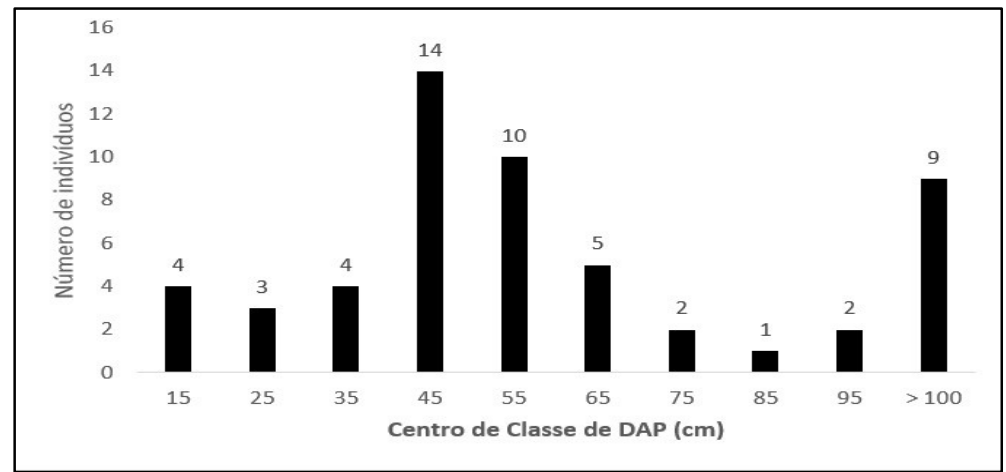

Figura 2: Distribuição dos indivíduos de Ficus por Classes de diâmetro à altura do peito, bairro Santa Clara, Santarém/Pará.

Gomes et al. (2016), em sua pesquisa sobre as características quali-quantitativas da arborização de uma praça urbana do Norte do Brasil, em Macapá, encontraram maior número de árvores com DAP <10 cm, indicando indivíduos jovens. Já Oliveira et al. (2018), em sua análise quali-quantitativa da arborização urbana da cidade de Acrelândia - Acre, constatou que 61,6\% das árvores possuíam diâmetro inferior a $30 \mathrm{~cm}$, seguidas por 31,6\% que estavam entre 30 e $40 \mathrm{~cm}$, demonstrando que ainda se encontram em fase de crescimento.

No que diz respeito ao direcionamento e posição, 100\% dos indivíduos foram classificados como retilíneos quanto ao fuste. Para a copa, 63\% estavam direcionados para a rua, $26 \%$ com copa sem inclinação e $11 \%$ com inclinação para as residências. Uma vez que a maioria dos indivíduos de fícus encontram-se nas calçadas e que grande parte do seu direcionamento de copa é voltado para as ruas, pode-se inferir que este cenário é resultante de podas realizadas por moradores do bairro, a fim de evitar que as copas das árvores prejudiquem a fiação de suas residências, o que justifica o baixo índice de copas voltadas para as mesmas.

O direcionamento das árvores para a rua pode consistir em uma problemática em relação a visualização da sinalização no tráfego de veículos, uma vez que sua copa pode dificultá-la. Outra possibilidade reside no apodrecimento de seus galhos, que pode gerar acidentes em sua queda. Sob diferente prisma, este cenário pode ser favorável de certa forma, uma vez que fornece sombra aos veículos estacionados em seu perímetro (MAZIOLI, 2012).

\section{Diâmetro de copa (DC)}

A maior concentração de indivíduos ocorreu na classe III, com 36 dos 54 indivíduos inventariados, seguidos por 13 e 5 indivíduos nas classes II e I, respectivamente. Os resultados de diâmetro de copa 
demonstram uma tendência de concentração de indivíduos na maior classe de tamanho, sucedido pelos de médio e menor diâmetro de copa (Figura 3).

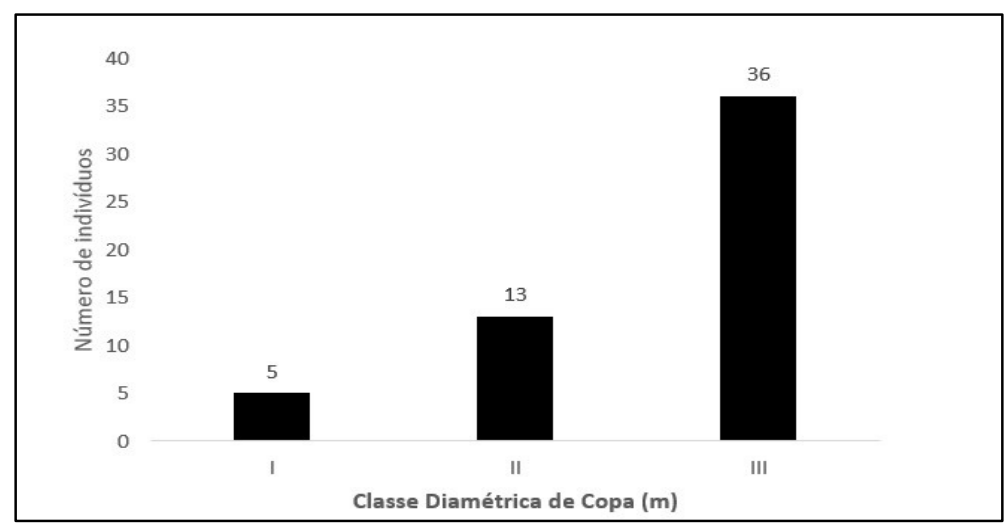

Figura 3: Distribuição dos indivíduos de Ficus por classe diamétrica de copa, Santarém, Pará, sendo: Classe I $(0 \leq \mathrm{DC}<$ $2,5 \mathrm{~m})$, Classe II $(2,5 \leq \mathrm{DC}<5 \mathrm{~m})$, Classe III (DC $\geq 5 \mathrm{~m})$.

O maior número de indivíduos na Classe III, com copa a partir de $5 \mathrm{~m}$ de diâmetro, demonstra que as árvores seguem a tendência de maior amplitude de copa, que é característico da espécie e principal motivo de sua utilização na arborização, devido principalmente ao seu valor paisagístico e geração de conforto térmico.

Resultados encontrados por Maria (2017), em seu estudo sobre a arborização de vias em Itanhaém$\mathrm{SP}$, constatou uma tendência de concentração de indivíduos $(78,9 \%)$ com menor área de copa $\left(0-30 \mathrm{~m}^{2}\right)$. Entretanto, dentre as espécies inventariadas, o Ficus benjamina apresentou a segunda maior cobertura vegetal, mas não se destaca em relação a área média de copa devido as modificações sofridas em sua copa através das podas de topiaria (MARIA, 2017).

\section{Porte}

A partir da análise da classificação de porte, constatou-se que 24 indivíduos (44\%) apresentam porte médio, 16 (30\%) porte pequeno e 14 (26\%) porte grande. Em análise conjunta com os dados de DAP, podemos inferir que o porte segue a mesma tendência da distribuição diamétrica (Figura 4).

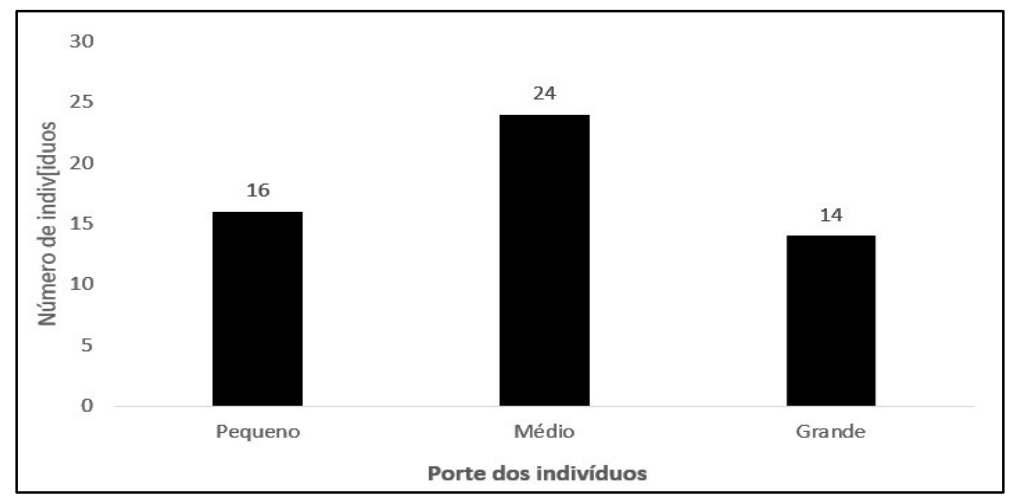

Figura 4: Distribuição dos indivíduos de Ficus por classe de porte, Santarém, Pará. Sendo: porte pequeno (5 m $\leq \mathrm{Ht}$ ), médio $(5 \leq \mathrm{Ht}<10 \mathrm{~m})$ e grande $(\mathrm{Ht} \geq 10 \mathrm{~m})$. 
Este cenário nos permite inferir que o predomínio da concentração em médio e pequeno porte pode ser resultante das constantes podas a que foram submetidos os indivíduos desta espécie ao longo dos anos, uma vez que seus dados de diâmetro de fuste indicam que não são, em sua maioria, indivíduos juvenis.

\section{Relação com a fiação}

No que diz respeito ao contato das árvores com a fiação (Figura 5), 56\% não estavam em contato e $44 \%$ tinham interação ou potencial para atingi-la ( $26 \%$ e $18 \%$, respectivamente).

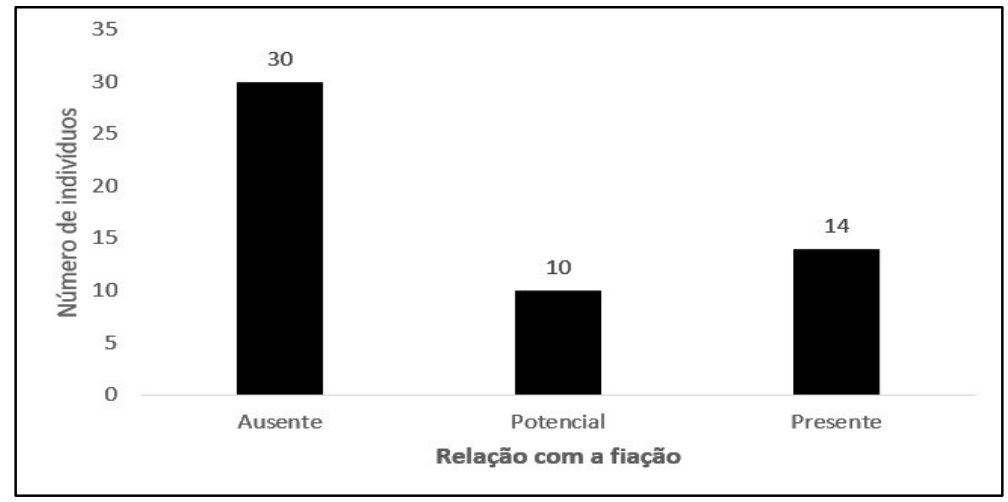

Figura 5: Relação entre a copa de Ficus e a fiação elétrica de acordo com seu nível de contato.

O percentual de indivíduos que apresentaram potencial ou contato com a fiação (44\%) é justificado pelo seu predomínio em médio porte (30\%), sendo que os indivíduos que ainda não atingiram a fiação se encontram nas classes menores de porte. A problemática na arborização pode ser classificada como danos causados às árvores ou pelas árvores (BOBROWSKI, 2014), neste caso, há problemática sendo gerada em ambos os sentidos. Os dados de fiação aqui presentes demonstram que o uso desta espécie não é adequado ao ambiente com presença de fiação aérea, uma vez que há potencial de conflito a partir do desenvolvimento do porte e da copa da árvore.

Levando em consideração a relação com a fiação, somado aos dados obtidos de porte e diâmetro de copa e se observando as potencialidades de desenvolvimento intrínsecas à espécie, podemos observar que os indivíduos causam conflitos com o meio devido a estes fatores, o que gera a necessidade de podas mais frequentes. De acordo com Gomes et al. (2016) a necessidade de maior frequência no emprego de podas em um indivíduo pode ser devido a inadequação de sua escolha em relação ao meio em que ele está inserido.

\section{Sanidade da raiz, copa e fuste}

Em relação a sanidade, $57 \%$ das raízes estavam com algum nível de podridão e $43 \%$ não apresentaram problemas. Para a sanidade do fuste, constou-se que $96 \%$ se encontravam sadias e $4 \%$ com algum nível de podridão. Na copa, $85 \%$ estavam sadias e $15 \%$ estavam com podridão ou presença de parasitas.

Oliveira (2012) estabelece que a avaliação de risco de uma árvore se refere ao ato de analisar as condições do indivíduo e verificar os danos ou possíveis danos ocasionados de alguma forma por um indivíduo arbóreo. Para tanto, é importante que dentro do contexto de inserção de árvores no ambiente 
urbano, sejam sempre aplicadas medidas de manutenção das mesmas, de modo a diminuir a ocorrência de árvores de risco e garantir sua sanidade.

É importante destacar que o fator arbóreo no meio urbano desempenha importantes funções. Por este motivo, é de fundamental importância que sejam mantidos níveis satisfatórios quanto a sanidade das árvores, permitindo que estas exerçam seu potencial benéfico tanto ao homem quando ao ambiente (NÓBREGA et al., 2014).

\section{Recomendação de manejo}

De acordo com as condições da árvore e da sua relação com o meio, baseados em avaliação visual, houve recomendação de manejo que indicou para a necessidade de poda em $81 \%$ das árvores, remoção do indivíduo em 6\% dos casos e ausência de necessidade de manejo em 13\% destes (Figura 6). Este panorama indica que a maioria dos indivíduos de Ficus apresenta necessidade de tratos silviculturais, seja por seu risco ou contato com a fiação elétrica, prejuízos ou potencialidades destes para com o meio.

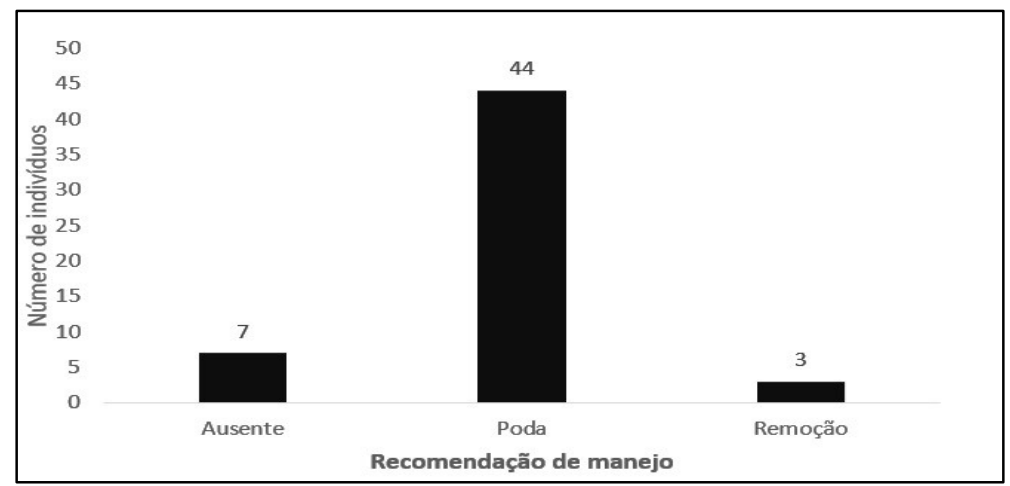

Figura 6: Recomendação de manejo de Ficus resultante da avaliação de suas condições fitossanitárias.

Muitos são os fatores que podem contribuir para a queda de árvores, entre elas estão a execução de podas inadequadas e a tentativa de contenção de raízes através de seu corte, o que favorece a ação de fitopatógenos, insetos, fungos e bactérias, afetando a sanidade da árvore e tornando-a suscetível ao seu apodrecimento e consequente queda (SAMPAIO, 2006; BRAZOLIN, 2009).

A poda se constitui de um importante elemento de manutenção das árvores, sendo benéfico se aplicada de forma apropriada. No entanto, quando realizada com muita frequência e por pessoas que não possuam a devida orientação para sua correta realização, é uma fonte de perigo e forte indicativo da não adequação dessas espécies ao meio (GOMES et al., 2016). Para Velasco (2003), apesar de a poda ser muito utilizada para que não haja interferência dos galhos para com a fiação, este trato estimula o surgimento de novas brotações que logo entrarão em contato com os fios novamente.

A necessidade de tratos silviculturais neste estudo está fortemente atrelada as demais condições na qual estas se encontram, a exemplo dos 24 indivíduos com potencial ou em contato com a fiação, resultante da altura predominantemente entre 5 e 10 metros e copa $\geq 5 \mathrm{~m}$, que gera necessidade de podas mais frequentes, para que não haja danos à rede elétrica. Outro indicativo crucial à recomendação de manejo é a sanidade do indivíduo e seu posicionamento em relação aos demais elementos, que em termos gerais se 
encontra em bom estado em relação à copa e fuste, mas nas raízes apresenta grande índice de podridão (57\%) e afloramento (83\%) em algum nível, gerando risco tanto à árvore, quanto ao meio. Tendo em vista esse cenário, nota-se que o uso de podas se torna mais frequente no Ficus devido as características inerentes à sua natureza.

Quanto a raiz, $83 \%$ apresentaram afloramento na calçada, sendo que que destes, $42 \%$ estavam causando danos ao pavimento, apenas $17 \%$ não apresentavam afloramento. Estes resultados mostram que as características de desenvolvimento das raízes não são compatíveis com ambientes pavimentados, corroborando com os estudos de Oliveira et al. (2010) e Lorenzi et al. (2003), que afirmam que a espécie Ficus apresenta um sistema radicular considerado superficial, o que pode ocasionar diversos danos à pavimentação do perímetro urbano. Oliveira et al. (2017) destacam ainda que essa problemática é devido ao reduzido espaço disponível para o adequado crescimento de suas raízes. Além disso, Barcellos et al. (2012) concluem que as espécies de raiz pivotante são mais apropriadas para este tipo de ambiente, devendo-se selecioná-las a fim de não ocasionar danos por elevação e destruição de calçadas, muros e asfaltos.

Carvalho et al. (2013), em sua pesquisa sobre o comportamento do Ficus benjamina para a arborização viária em Serra Talhada/PE, relacionaram a menor largura da calçada com a frequência do levantamento pesado de sua pavimentação, ocasionado pelo desenvolvimento radicular e afloramento deste na calçada, sendo favorecido por estas circunstâncias.

O cultivo de Ficus em Santarém apresenta a problemática do não planejamento quanto a sua implantação e disposição no meio, ocasionando problemas tanto por parte de sua copa, que entra em conflito com a rede elétrica, quanto pelo desenvolvimento de suas raízes. Tais circunstâncias, segundo Oliveira (2018) e Martins et al. (2010), levam a população a realizar podas drásticas que comprometem a sanidade da árvore, tornando-a suscetível ao ataque de agentes externos, acarretando em perdas estéticas do indivíduo ou em casos mais graves a sua morte.

\section{CONCLUSÕES}

Grande parte dos indivíduos de Ficus causa danos ao meio urbano ou tem potencialidade para tal, faltando-lhes, neste segundo caso, apenas seu amadurecimento quando indivíduo, no caso de árvores mais jovens e uma pausa maior entre as podas que Ihes são conferidas. Conclui-se que a utilização do Ficus não é adequada para a arborização em meio a estruturas pavimentadas ou próxima a fiação devido às suas características de copa, fuste e raízes, sendo mais adequado seu uso em ambientes não citadinos. Deste modo, aconselha-se ainda a sua substituição de forma gradativa de calçadas e dos acessos viários da cidade, substituindo-as por espécies nativas mais compatíveis com as propostas e necessidades da arborização urbana da cidade.

\section{REFERÊNCIAS}

ÁVILA, M. R.. Cenários da expansão urbana e da legislação e os reflexos na cobertura vegetal arbórea e arbustiva na cidade de Americana/SP. 2015
BARCELLOS, A.; WOJCIKIEWICZ, C. R.; LUBASZEWSKI. E. A.; MAZUCHOWSKI, J. Z.; CONCEIÇÃO, J. R.; LEAL, L.; MEDEIROS, 
M. L. M.; CONTE, P. A.; KARVAT, S. G.; AHRENS, S.. Manual para elaboração do plano municipal de arborização urbana. 2012.

BRAZOLIN, S.. Biodeterioração, anatomia do lenho e análise de risco de queda de árvores de tipuana, Tipuana tipu (Benth.) O. Kuntze, nos passeios públicos da cidade de São Paulo, SP. Tese (Doutorado em Recursos Florestais) Universidade de São Paulo, Piracicaba, 2009.

\section{BOBROWSKI, R.. Gestão da arborização de ruas:} ferramentas para o planejamento técnico e participativo. Tese (Doutorado em Engenharia Florestal) - Universidade Federal do Paraná, Curitiba, 2014.

BLUM, C. T.; BORGO, M.; SAMPAIO, A. C. F.. Espécies exóticas invasoras na arborização de vias públicas de Maringá/PR. Revista da Sociedade Brasileira de Arborização Urbana, v.3, n.2, p.78-97, 2008.

CABRAL, P. I. D.. Arborização Urbana: problemas e benefícios. Revista Especialize IPOG, Goiânia, n.6, p.1-15, 2013.

CARVALHO, A. A.; SILVA, L. F.; LIMA, A. P.; SANTOS, T. P.. A inviabilidade do Ficus (Ficus benjamina L.) para a arborização viária. In: JORNADA DE ENSINO, PESQUISA E EXTENSÃO JEPEX, 13. Anais. Recife: Universidade Federal Rural de Pernambuco, 2013.

COELHO, M. C. N.. Impactos ambientais em áreas urbanas Teorias, conceitos e métodos de pesquisa. In: GUERRA, A. J. T.; CUNHA, S. B.. Impactos ambientais urbanos no Brasil. Rio de Janeiro: Bertrand Brasil, 2004, p.19-45.

LIRA FILHO, J. A.; FONSECA, C. M. B.; ALVESZ, P. S.; LACERDA, R. M. A.. Experiência piloto em arborização participativa em duas cidades de pequeno porte do semiárido brasileiro. Revista da Sociedade Brasileira de Arborização Urbana, v.4, n.2, p.1-15, 2009.

EMBRAPA. Empresa Brasileira de Pesquisa Agropecuária. Clima. Brasília: Embrapa, 2019.

GOMES, E. M. C.; RODRIGUES, D.; SANTOS, J. T.; BARBOSA, E.. Análise quali-quantitativa da arborização de uma praça urbana do Norte do Brasil. Nativa, Sinop, v.4, n.3, p.179-186, 2016.

IBGE. Instituto Brasileiro de Geografia e Estatística. Panorama de Santarém. Rio Janeiro: IBGE, 2010.

IBGE. Instituto Brasileiro de Geografia e Estatística. Bases e referenciais: bases cartográficas: malhas-digitais. Rio Janeiro: IBGE, 2015.

IBGE. Instituto Brasileiro de Geografia e Estatística. Panorama de Santarém. Rio Janeiro: IBGE, 2019.

IMRAN, M.; RASOOL, N.; RIZWAN, K.; ZUBAIR, M.. Chemical composition and Biological studies of Ficus benjamina. Chemistry Central Journal, v.8, n.1, p.12, 2014.

JORGE, V. C.; OESTREICH, E. F.; MAMEDE, J. S. S.; NASCIMENTO, D. A.; SOUZA, M. D.; SILVA J. G. J.; DORVAL, A.. Diagnóstico fitossanitário da arborização urbana no bairro Cidade Alta, Cuiabá Mato Grosso, Brasil. Revista Espacios, v.38, n.41, 2017.

LORENZI, H.; SOUZA, H. M.; TORRES, M. A. V.; BACHER, L. B. Árvores exóticas no Brasil. Nova Odessa: Instituto Plantarum, 2003.

MARIA, T. R. B. C.. Inventário quali-quantitativo de arborização viária do município de Itanhaém-SP. Dissertação (Mestrado) - Universidade Federal do Paraná, Curitiba, 2017.

MARTINS, L. F. V.; ANDRADE, H. H. B.; ANGELIS, B. L. D.. Relação entre podas e aspectos fitossanitários em árvores urbanas na cidade de Luiziana, Paraná. Revista da Sociedade Brasileira de Arborização Urbana, Piracicaba, v.5, n.4, p.141-155, 2010.

MAZIOLI, B. C.. Inventário e diagnóstico da arborização urbana de dois bairros da cidade de Cachoeiro do Itapemirim, ES. Monografia (Graduação em Engenharia Florestais) - Universidade Federal do Espírito Santo, Jerônimo Monteiro, 2012

MOURA, T. A.; SANTOS, V. L. L. V.. Levantamento qualiquantitativo de espécies arbóreas e arbustivas na arborização viária urbana dos bairros centro e centro norte, Várzea Grande, Mato Grosso, Brasil. Revista da Sociedade Brasileira de Arborização Urbana, Piracicaba, v.1, n.1, p.97117, 2009.

MUSEU NACIONAL. Ficus benjamina no Museu Nacional da UFRJ. Rio de Janeiro: MUSEU NACIONAL, 2019.

NÓBREGA, C. C.; SOUTO, P. C.; ARAÚJO, L. H. B.; SILVA, A. C. F.; PINTO, M. G.. Análise quanti-qualitativa das espécies arbóreas presentes no Parque Religioso Cruz da Menina, Patos/PB. Enciclopédia Biosfera, Goiânia, v.10, n.18, 2014.

OLIVEIRA, A.; CARVALHO, S. M.. Arborização de vias públicas e aspectos socioeconômicos de três vilas de Ponta Grossa, PR. Revista da Sociedade Brasileira de Arborização Urbana, Piracicaba, v.5, n.3, p.42-58, 2010.

OLIVEIRA, G. N.. Revitalização da Arborização Urbana no Centro de Governador Valadares/MG. Lavras, 2012.

OLIVEIRA, L. M.; SANTOS, A. F.; SOUZA, P. A.; ALVES, K. C. C. L. F.; GIONDO, M.. Diagnóstico da arborização nas calçadas de Gurupi, TO. Revista da Sociedade Brasileira de Arborização Urbana, v.12, n.1, p.105-121, 2017. DOI: http://dx.doi.org/10.5380/revsbau.v12i1.63515

OLIVEIRA, R. C. D.; BEZERRA, T. G.; VIEIRA, T. A.. Arborização urbana com nim indiano na cidade de Santarém, Pará, Brasil. Revista da Sociedade Brasileira de Arborização Urbana, v.13, n.2, p.37-46, 2018. DOI: http://dx.doi.org/10.5380/revsbau.v13i2.63643

SAMPAIO, A. C. F.. Análise da arborização de vias públicas das principais zonas do plano piloto de Maringá/PR. Dissertação (Mestrado em Geografia, área de concentração Análise Regional e Ambiental) - Universidade Estadual de Maringá, Maringá, 2006.

SANTOS, R. C.; ANTUNES, L.; BESSEGATTO, D.. Espécies exóticas invasoras na arborização urbana de vias públicas de 
Sananduva/RS. Revista Brasileira de Arborização Urbana, Piracicaba, v.12, n.2, p.39-47, 2017.

SILVA, J. D.; NETO, F. D. P.. Princípios básicos de dendrometria. Recife: Universidade Federal Rural de Pernambuco, 1979.

SILVA, A. A. R.; VERAS, C. H. G.; MACHADO, J. C.; SOUSA, J. F.; LEAL, M. A. S.; SILVA, M. J. S.; MENDES, M. R. A.. Diagnóstico da arborização do bairro são benedito, município de Parnaíba, Piauí. Revista da Sociedade Brasileira de Arborização Urbana, v.13, n.4, p.29-40, 2018. DOI: http://dx.doi.org/10.5380/revsbau.v13i4.64900
SOUZA, V. C.; LORENZI, H.. Botânica sistemática: um guia ilustrado para identificação das famílias de Angiospermas da flora brasileira, baseado em APG II. Nova Odessa: Instituto Plantarum, 2005.

VELASCO, G. D. N.. Arborização viária x sistema de distribuição de energia elétrica: Avaliação dos custos, estudo das podas e levantamento de problemas fitotécnicos. Dissertação (Mestrado em Fitotecnia) - Universidade Superior de Agricultura Luiz de Queiroz, Piracicaba, 2003.

A CBPC - Companhia Brasileira de Produção Científica (CNPJ: 11.221.422/0001-03) detém os direitos materiais desta publicação. Os direitos referem-se à publicação do trabalho em qualquer parte do mundo, incluindo os direitos às renovações, expansões e disseminações da contribuição, bem como outros direitos subsidiários. Todos os trabalhos publicados eletronicamente poderão posteriormente ser publicados em coletâneas impressas sob coordenação da Sustenere Publishing, da Companhia Brasileira de Produção Científica e seus parceiros autorizados. Os (as) autores (as) preservam os direitos autorais, mas não têm permissão para a publicação da contribuição em outro meio, impresso ou digital, em português ou em tradução. 